\title{
Social Isolation and Cardiovascular Health in US Adults
}

\author{
Chi Kieu, ${ }^{1}$ Susan Behforooz, ${ }^{1}$ Nathan D Wong, ${ }^{1}$
}

\section{Abstract}

Background/Aim: The relation of social isolation (SI) to global cardiovascular health (CVH) is not clear. In this paper the association of CVH metrics to SI within US adults was investigated.

Methods: Using the US National Health and Nutrition Examination Survey, the association of SI with American Heart Association's Life's Simple 7 (LS7) CVH components (smoking, body mass index, physical activity, total cholesterol, diet, blood pressure, fasting blood glucose) was examined. The sum of the components (scored 1 for poor, 2 for intermediate and 3 for ideal) created a composite CVH score. Multiple logistic regression provided the odds of SI according to levels of the LS7 components adjusted for age, sex, and ethnicity.

Results: A total of 3,528 adults aged $\geq 40$ were studied. The mean age, sex and ethnicity-adjusted composite CVH scores were $14.1 \mathrm{vs} 14.6$ in those with vs without SI ( $p$ <.01). Multiple logistic regression examined individual LS7 components in relation to SI and showed the adjusted odds for SI for those with ideal vs poor smoking status to be 0.57 (range $0.38-0.85$ ), ideal vs poor physical activity 0.53 (range 0.37-0.76) and ideal vs poor fasting glucose 0.65 (range 0.47-0.91).

Conclusion: This study generally shows lower levels of CVH in those with vs without SI, with non-smoking status; ideal physical activity and ideal glucose levels were all less likely associated with SI, suggesting the potential value for screening for SI in identifying those at potential cardiovascular disease risk.

Key words: cardiovascular health, social isolation, risk factors.

(1) Heart Disease Prevention Program, Division of Cardiology, University of California, Irvine, CA, USA.

Correspondence: NATHAN D WONG

E: ndwong@uci.edu

\section{Introduction}

Social support is a key psychosocial factor that has a prominent and powerful impact on physical and mental health. Previous research has indicated that there is a decreased risk of mortality in those with significant quality or quantity of social connections compared to those with low quality or quantity of social networks, when adjusted for baseline health status. ${ }^{1}$ Subsequently, data show that psychosocial factors, including low social support, are correlated to greater risk of cardiovascular disease (CVD). ${ }^{2-6}$ The impact of social relationships on cardiovascular health has also been shown to be comparable with that of stan- dard traditional risk factors. ${ }^{7}$ In addition, social connections have been shown to be associated with the development and progression of CVD. ${ }^{8-13}$

The American Heart Association (AHA) had set a goal to improve cardiovascular health $(\mathrm{CVH})$ of the general American population by $20 \%$ by the year of 2020. The AHA promotes and encourages primary prevention of CVD by describing 7 cardiovascular and behavioural health factors or Life's Simple 7 (LS7) including fasting glucose, blood pressure, total cholesterol, body mass index (BMI), smoking, diet and physical activity as 
poor, intermediate and ideal. ${ }^{14}$ Although the relation of these metrics with heart failure, ${ }^{15},{ }^{16} \mathrm{CVD},{ }^{17}$ chronic pulmonary obstructive disease ${ }^{18}$ and cancer19 have been shown, no study has examined the connection between social isolation and the metrics of CVH. This study examines the relation of social isolation (SI) with AHA's LS7 metrics of $\mathrm{CVH}$, in an effort to further document the role of inadequate social support in CVH.

\section{Methods}

A total of 3,528 adults aged $\geq 40$ from the National Health and Nutrition Examination Survey (NHANES) were examined. NHANES is a cross-sectional, multistage, stratified, clustered probability sample of the US non-institution- alised population conducted by the Centers for Disease Control and Prevention's National Center for Health Statistics (NCHS). Participants underwent a clinical examination including blood collection and answering a household interview; the

Table 1. AHA's Life's Simple 7 Measures

\begin{tabular}{|c|c|c|c|}
\hline & Poor & Intermediate & Ideal \\
\hline Smoking & Yes & Former or quit $\leq 12$ months prior & Never or quit $>12$ months prior \\
\hline Body Mass Index & $\geq 30 \mathrm{~kg} / \mathrm{m}^{2}$ & $25.0-29.9 \mathrm{~kg} / \mathrm{m}^{2}$ & $<25.0 \mathrm{~kg} / \mathrm{m}^{2}$ \\
\hline Physical Activity & None & $\begin{array}{l}\text { 1-149 } \mathrm{min} / \mathrm{wk} \text { moderate intensity } \\
1-74 \mathrm{~min} / \mathrm{wk} \text { vigorous intensity or } \\
1-149 \mathrm{~min} / \mathrm{wk} \text { moderate+vigorous }\end{array}$ & $\begin{array}{l}\geq 150 \mathrm{~min} / \text { wk moderate intensity } \\
\geq 75 \mathrm{~min} / \text { wk vigorous or } \\
\geq 150 \mathrm{~min} / \text { wk moderate+vigorous }\end{array}$ \\
\hline Diet & $0-1$ & 2-3 components & $4-5$ components \\
\hline Total Cholesterol & $\geq 240 \mathrm{mg} / \mathrm{dL}$ & $200-239 \mathrm{mg} / \mathrm{dL}$ or treated to goal & $<200 \mathrm{mg} / \mathrm{dL}$ untreated \\
\hline Blood Pressure & $\begin{array}{l}\text { Systolic } \geq 140 \text { or } \\
\text { Diastolic } \geq 90 \mathrm{mmHg}\end{array}$ & $\begin{array}{l}\text { Systolic } 120-139 \text { or Diastolic } 80-89 \mathrm{mmHg} \\
\text { or treated to goal }\end{array}$ & $<120 /<80 \mathrm{mmHg}$ untreated \\
\hline $\begin{array}{l}\text { Fasting Blood } \\
\text { Glucose }\end{array}$ & $\geq 126 \mathrm{mg} / \mathrm{dL}$ & $100-125 \mathrm{mg} / \mathrm{dL}$ or treated to goal & $<100 \mathrm{mg} / \mathrm{dL}$ untreated \\
\hline
\end{tabular}

precise methods and study design for NHANES have been previously described. ${ }^{20,}{ }^{21}$ The study was conducted using data from 2007-2008, which is the last wave of data that includes social support questionnaires. Participants aged $<40$ years were excluded, as they were not included in the sample given social support questionnaires. All participants gave a written informed consent. The current analysis utilised de-identified data from NHANES and was thus exempt from institutional review board approval.

The primary measure of social support was self-reported through a household questionnaire, which queried the participant as to whether there is anyone to provide adequate social support for both male and female participants. Participants who answered negatively for this question were indicated as being socially isolated.

Based on the American Heart Association's Life's Simple 7, each of the 7 health factors and behaviours including diet, BMI, blood pressure, total cholesterol, fasting blood glucose, smoking status, and physical activity were classified as poor, intermediate, and ideal; specific and detailed descriptions of individual metrics are presented in Table 1.

Participants scoring poor for an individual measure were given a score of 1 , intermediate score of 2, or ideal score of 3, respectively. Aggregating the scores assigned for the 7 metrics, a cumulative Life's Simple 7 score (LS7 score) was calculated from the sum of all 7 individual risk factor scores, resulting in a cumulative range of 7 to 21 . A score of 7 correlated to the poorest health and 21 corresponded to optimal health.

Analysis of variance (ANOVA) was performed to compare the means of LS7 among subjects with and without SI, while adjusting for age, gender, and ethnicity. Additionally, logistic regression was used to calculate the odds of SI, comparing ideal and intermediate versus poor levels for all the LS7 measures adjusting for age, gender, and ethnicity. Any and all statistical analyses and/or computation of weighted estimates for the general US population were performed using SAS version 9.0.3 (SAS Institute Inc.). 


\section{Results}

A total of 3,528 adults aged $\geq 40$ were included (50.9 \% females, 18.8 \% African American, 26.2 \% Hispanics). Of the total study population, 90.4 $\%$ were classified as being absent of SI (having social support) and $9.6 \%$ being socially isolated. The mean adjusted composite CVH score was 14.6 without vs 14.1 in those who were socially isolated $(\mathrm{p}<0.01)$. There were significantly lower proportions of persons with ideal levels of physical activity and fasting blood glucose in those who were socially isolated $(\mathrm{p}<0.01)$. Among those who were socially isolated compared to those who were not, there were higher proportions who were Hispanic (26.1\% vs 8 . 6\%) but lower proportions who were African American (7.7\% vs 9.7 \%) (both p < 0.01) (Table 2).Multiple logistic re-

Table 2. Demographic characteristics comparing those with versus without social isolation

\begin{tabular}{|c|c|c|c|}
\hline Measures & $\begin{array}{l}\text { Social Isolation Absent } \\
(n=3191,90.4 \%)\end{array}$ & $\begin{array}{l}\text { Social Isolation Present } \\
(\mathrm{n}=337,9.6 \%)\end{array}$ & p-value \\
\hline Age (mean \pm SD) & $56.9 \pm 0.33$ & $57.5 \pm 0.68$ & 0.46 \\
\hline Female $(\%)$ & $6.2 \mathrm{M}(52.9 \%)$ & $4.0 \mathrm{M}(49.5 \%)$ & 0.44 \\
\hline African American (\%) & $11.3 \mathrm{M}(9.7 \%)$ & $0.6 \mathrm{M}(7.7 \%)$ & $<0.0001$ \\
\hline Hispanics (\%) & $6 \mathrm{M}(8.6 \%)$ & $2.1 \mathrm{M}(26.1 \%)$ & $<0.0001$ \\
\hline Total Cholesterol, mg/dL (mean \pm SD) & $202.4 \pm 1.07$ & $208.7 \pm 3.53$ & 0.119 \\
\hline HDL-Cholesterol, mg/dL (mean \pm SD) & $52.9 \pm 0.54$ & $51.3 \pm 1.26$ & 0.176 \\
\hline Systolic Blood Pressure, mmHg (mean \pm SD) & $125.8 \pm 0.49$ & $127.8 \pm 1.27$ & 0.116 \\
\hline Diastolic Blood Pressure, mmHg (mean \pm SD) & $71.9 \pm 0.42$ & $72.1 \pm 0.79$ & 0.835 \\
\hline Body Mass Index, $\mathrm{kg} / \mathrm{m}^{2}($ mean \pm SD) & $28.8 \pm 0.14$ & $28.5 \pm 0.49$ & 0.44 \\
\hline \multicolumn{4}{|l|}{ AHA Life's Simple 7 Measures (\%): } \\
\hline \multicolumn{4}{|l|}{ Smoking } \\
\hline Current & 18.8 & 24.9 & \multirow{3}{*}{0.086} \\
\hline Past & 1.97 & 3.73 & \\
\hline Never & 79.2 & 71.3 & \\
\hline \multicolumn{3}{|l|}{ Obesity } & \multirow{4}{*}{0.714} \\
\hline Obese & 35.3 & 33.3 & \\
\hline Overweight & 36.7 & 40.1 & \\
\hline Normal & 27.9 & 26.5 & \\
\hline \multicolumn{3}{|l|}{ Total Cholesterol } & \multirow{4}{*}{0.323} \\
\hline Poor & 17.6 & 23.2 & \\
\hline Intermediate & 48.0 & 43.3 & \\
\hline Ideal & 34.3 & 33.5 & \\
\hline \multicolumn{3}{|l|}{ Blood Pressure } & \multirow{4}{*}{0.492} \\
\hline Poor & 21.9 & 25.4 & \\
\hline Intermediate & 50.4 & 47.8 & \\
\hline Ideal & 21.9 & 26.7 & \\
\hline \multicolumn{3}{|l|}{ Diet } & \multirow{4}{*}{0.474} \\
\hline Poor & 73.5 & 70.1 & \\
\hline Intermediate & 22.3 & 23.6 & \\
\hline Ideal & 4.21 & 6.32 & \\
\hline \multicolumn{3}{|l|}{ Exercise } & \multirow{4}{*}{0.0002} \\
\hline Poor & 26.8 & 37.9 & \\
\hline Intermediate & 46.3 & 41.0 & \\
\hline Ideal & 26.9 & 21.0 & \\
\hline \multicolumn{3}{|l|}{ Fasting Blood Glucose } & \multirow{4}{*}{0.0092} \\
\hline Poor & 12.2 & 18.5 & \\
\hline Intermediate & 16.8 & 17.9 & \\
\hline Ideal & 71.0 & 63.5 & \\
\hline *AHA Life's Simple 7 Score (mean \pm SD) & $14.6 \pm 0.09$ & $14.1 \pm 0.11$ & 0.003 \\
\hline
\end{tabular}


gression (Table 3) shows that compared to participants those at poor levels of health metrics, the age, ethnicity, and gender-adjusted odds (95\%) for social isolation among those at ideal fasting blood glucose were $65 \%(\mathrm{p}<0.05)$ as likely to be socially isolated. Compared to non-smokers, cur-

Table 3. Multivariable logistic regression odds of social isolation among AHA's LS7 measures

\begin{tabular}{|c|c|c|}
\hline Measures & Odds Ratio (95 \% Cl) & p-value \\
\hline Age (per 10 years) & $1.09(0.95-1.26)$ & 0.2113 \\
\hline Female (vs. Male) & $0.81(0.58-1.13)$ & 0.2148 \\
\hline Black (vs. White) & $0.88(0.51-1.53)$ & 0.6460 \\
\hline Hispanics (vs. White) & $4.00(2.94-5.44)$ & $<0.0001$ \\
\hline Other Race (vs. White) & $2.94(1.67-5.20)$ & 0.0002 \\
\hline Diet 2 vs. 1 & $1.01(0.67,1.51)$ & 0.9727 \\
\hline Diet 3 vs. 1 & $1.49(0.58,3.77)$ & 0.4026 \\
\hline BMI 2 vs. 1 & $1.21(0.86,1.69)$ & 0.2688 \\
\hline BMI 3 vs. 1 & $1.06(0.70,1.61)$ & 0.7710 \\
\hline Blood Pressure 2 vs. 1 & $0.88(0.63,1.24)$ & 0.4629 \\
\hline Blood Pressure 3 vs. 1 & $0.92(0.60,1.42)$ & 0.7251 \\
\hline Total Cholesterol 2 vs. 1 & $0.72(0.46,1.12)$ & 0.1439 \\
\hline Total Cholesterol 3 vs. 1 & $0.76(0.42,1.39)$ & 0.3807 \\
\hline Fasting Blood Glucose 2 vs. 1 & $0.77(0.49,1.21)$ & 0.2646 \\
\hline Fasting Blood Glucose 3 vs. 1 & $0.65(0.47,0.91)$ & 0.0117 \\
\hline Smoking 2 vs. 1 & $1.39(0.39,4.88)$ & 0.6112 \\
\hline Smoking 3 vs. 1 & $0.57(0.38,0.85)$ & 0.0061 \\
\hline Physical Activity 2 vs. 1 & $0.73(0.54,0.99)$ & 0.0446 \\
\hline Physical Activity 3 vs. 1 & $0.53(0.37,0.76)$ & 0.0006 \\
\hline
\end{tabular}

rent smokers were $57 \%(\mathrm{p}<0.01)$ as likely to be socially isolated. Those who were at an ideal level of physical activity were $53 \%(\mathrm{p}<0.001)$ as likely and intermediate levels of physical activity to be $73 \%$ as likely $(\mathrm{p}<0.05)$ to be socially isolated. While age and sex did not relate significantly to the likelihood of social isolation, in adjusted analyses, compared to whites, Hispanics were 4 times more likely and other races 2.9 times more likely to be social isolated (both $\mathrm{p}<0.01$ ).

\section{Discussion}

This study is the first to examine and analyse the relation between AHA's LS7 metrics and social isolation (also defined within the literature as "lack of social support"), in a representative sample of the US population. The primary finding of this study was that lack of social isolation (presence of social support) was associated with greater levels of cardiovascular health measured by LS7. In particular, it was found that among the LS7 components, social isolation is associated with poorer fasting blood glucose, smoking, and physical activities. Moreover, Hispanics were four times as likely as whites to be socially isolated.

Smoking is strongly associated with social isolation and current smokers are more likely to be socially isolated. Although there are discrepancies in the findings, ${ }^{22}$ social support has been shown to be associated with successful smoking cessation. ${ }^{23}$ With a smoking prevalence of $15.2 \%$ among adults age $\geq 18$ in $2015,{ }^{24}$ the presence of social support will be quite beneficial at the reduction of smoking prevalence among the population thus contributing to an improved general cardiovascular health. While smoking is a critical risk factor, the reduction of smoking prevalence in the recent years has been counterproductive by the increase of poor blood pressure, BMI, and absence of healthy diet ${ }^{25}$ resulting in the need to consider other factors for primary prevention of CVD.

Physical activity is an important factor of LS7 and hold a significant correlation with SI where those with intermediate and ideal level of physical activities are less likely to be socially isolated. Many prior studies have established that physical activity is positively related to social support.26-29 Females with high physical activity social support were twice as likely to be active at least $30 \mathrm{~min}$ utes for 5 or more days per week..$^{30}$ Absence of friend or family support has been shown 23-55\% more likely to be inadequately active comparing to those with high family or friend support. ${ }^{31}$ The influence of physical activity on other factors such as blood glucose are rather essential in the primary prevention of CVD, thus the presence of social support influencing physical behaviour may be advantageous in the reduction of blood glucose indirectly through the increase of physical activity.

Previous studies have indicated that social support is associated with better diabetes self-management. ${ }^{32-34}$ Furthermore, social support at higher levels are related with improved glycaemic control, enhanced adherence of treatment, and strengthened life's quality; although the relationship is controversial and debated. ${ }^{35-39}$ While the relation between social support and blood glucose is indirect, the significance of social support in diabetes care remains a prominent factor as it has been shown to be valuable in diagnosis acceptance, adjusting emotionally, and stress alleviation. ${ }^{39,40}$ 
The clinical implication of this study is that the promotion of social support is essential to $\mathrm{CVH}$. These findings may help to explain the link between SI and increased CVD risk, but further study is warranted to confirm this. The individualist culture within the US population may interfere with effective and sufficient prevention of diseases such as CVD. The findings should be an encouragement for the general public to seek out and maintain strong social relationships, as it yields improvement with respect to quality of life. Additionally, clinicians may be able to improve patient outcomes by assessing social support and intervening more aggressively in those who are socially isolated.

This study only assessed the presence of SI and not the degree or specific type of SI, thus future study is needed to examine the relation between the type of social support or SI and CVH. To some individuals, having a family member is considered as social support but others may find having a peer equally, if not more, beneficial; the discrepancies between the relationships pose potential challenges when it comes to quantifying social support. Depending on the individual's personality and preferences, some may prefer to have a large group of friends while others enjoy a small intimate group of peers, but both are perceived as sufficient support. Quantity of social connections does not convey quality.

This study has strengths and limitations. The key strength of the National Health and Nutrition Examination Survey is the inclusion of a US-population representative sample of adults with data generalisable to the greater US population. However, due to the limitation of the NHANES social support variable, there was no ability to analyse quality vs quantity of social support, thus warranting future studies. Furthermore, the measure of SI used in this study was only based on one NHANES question with respect to self-reported presence of social support due to significant missing values. This information was only available from the 2007-2008 NHANES survey and not more recent ones; however, the association between social isolation and cardiovascular health factors is not anticipated to depend on the survey year (unlike assessing prevalence information of risk factors). Finally, the cross-sectional nature of the study remains a limitation of the study. This warrants further longitudinal studies in individuals initially free of SI at baseline to determine the prospective relation of $\mathrm{CVH}$ such as $\mathrm{LS} 7$ with the actual development of SI.

\section{Conclusion}

This study shows a higher level of CVH in those with social support compared to those with social isolation, with non-smoking status, ideal physical activity, and glucose levels components independently associated a lower likelihood of SI, warranting the consideration of screening for SI as a possible determinant of CVD risk. Prospective study should examine how social isolation may lead to a declining cardiovascular risk factor profile.

\section{Acknowledgments}

None.

\section{Conflict of interest}

None.

\section{References}

1. Berkman LF, Glass T, Brissette I, Seeman TE. From social integration to health: Durkheim in the new millennium. Soc Sci Med 2000;51:843-57.

2. Aldana SG, Whitmer WR, Greenlaw R, Avins AL, Thomas D, Salberg A, et al. Effect of intense lifestyle modification and cardiac rehabilitation on psychosocial cardiovascular disease risk factors and quality of life. Behav Modif 2006;30:507-25.

3. Compare A, Germani E, Proietti R, Janeway D. Clinical psychology and cardiovascular disease: an up-to-date clinical practice review for assessment and treatment of anxiety and depression. Clin Pract Epidemiol Ment Health 2011;7:148-56.

4. Claesson M, Burell G, Birgander LS, Lindahl B, Asplund K. Psychosocial distress and impared quality of life-targets neglected in the secondary prevention in women with ischaemic heart disease. Eur J Cardiovasc Prev Rehabil 2003;10:258-66.

5. Fukuoka Y, Lindgren TG, Rankin SH, Cooper BA, Carroll DL. Cluster analysis: a useful technique to identify elderly cardiac patients at risk for poor quality of life. Qual Life Res 2007; 16:1655-63.

6. Rozanski A, Blumenthal JA, Davidson KW, Saab PG, Kubzansky L. The epidemiology, pathophysiology, and management of psychosocial risk factors in cardiac practice: the emerging field of behavioral cardiology. $\mathrm{J}$ Am Coll Cardiol 2005;45:637-51.

7. House JS, Landis KR, Umberson D. Social relationships and health. Science 1988;241:540-5. 
8. Knox SS, Adelman A, Ellison RC, Arnett DK, Siegmund $\mathrm{K}$, et al. Hostility, social support and carotid artery atherosclerosis in the National Heart, Lung, and Blood Institute Family Heart Study. Am J Cardiol 2000;86:1986-9.

9. Kop WJ, Berman DS, Gransar H, Wong ND, Miranda-Peats R, et al. Social network and coronary artery calcification in asymptomatic individuals. Psychosom Med 2005;667:343-52.

10. Brummet BH, Barefoot JC, Siegler IC, Clapp-Channing $\mathrm{NE}$, Lytle BL, et al. Characteristics of socially isolated patients with coronary artery disease who are at elevated risk for mortality. Psychosom Med 2001;63:267-72.

11. Wang HX, Mittleman MA, Leineweber C, Orth-Gomer $\mathrm{K}$. Depressive symptoms, social isolation, and progression of coronary atherosclerosis: the Stockholm Female Coronary Angiography Study. Psychother Psychosom 2006;75:96-102.

12. Wang HX, Mittleman MA, Orth-Gomer K. Influence of social support on progression of coronary artery disease in women. Soc Sci Med 2005;60:599-607.

13. World Health Organization. Cardiovascular diseases (CVDs) fact sheets. World Health Organization website. www.who.int/mediacentre/factsheets/fs317/en/. Published May 2017. Accessed 2017-11-19.

14. Lloyd-Jones DM, Hong Y, Labarthe D, Mozaffarian D, Appel LJ, Van Horn L, et al; American Heart Association Strategic Planning Task Force and Statistics Committee. Defining and setting national goals for cardiovascular health promotion and disease reduction: the American Heart Association's strategic Impact Goal through 2020 and beyond. Circulation 2010;121:586613.

15. Folsom AR, Yamagishi K, Hozawa A, Chambless LE; Atherosclerosis Risk in Communities Study Investigators. Absolute and attributable risks of heart failure incidence in relation to optimal risk factors. Circ Heart Fail 2009;2:11-7.

16. Avery CL, Loehr LR, Baggett C, Chang PP, Kucharska-Newton AM, Matsushita K, et al. The population burden of heart failure attributable to modifiable risk factors: the ARIC (Atherosclerosis Risk in Communities) study. J Am Coll Cardiol. 2012; 60:1640-6.

17. Folsom AR, Yatsuya H, Nettleton JA, Lutsey PL, Cushman M, Rosamond WD, et al. Community prevalence of ideal cardiovascular health, by the American Heart Association definition, and relationship with cardiovascular disease incidence. J Am Coll Cardiol 2011;57:1690-6.

18. Fan W, Lee H, Lee A, Kieu C, Wong ND. Association of lung function and chronic obstructive pulmonary disease with American Heart Association's Life Simple 7 cardiovascular health metrics. Resp Med 2017;13:8593.

19. Rasmussen-Torvik LJ, Shay CM, Abramson JG, Friedrich CA, Nettleton JA, Prizment AE, et al. Ideal cardiovascular health is inversely associated with incident cancer: the Atherosclerosis Risk In Communities study. Circulation 2013; 127:1270-5.

20. Centers for Disease Control and Prevention. National Health and Nutrition Examination Survey: questionnaires, data sets, and related documentation. National Center for Health Statistics; 2010.

21. Dwyer J, Picciano MF, Raiten DJ, Steering Committee. Collection of food and dietary supplement intake data: what we eat in America-NHANES. J Nutr 2003;133(2):590S-600S.

22. Malott JM, Glasgow RE, O’Neil HK, Klesges RC. Co-worker social support in a worksite smoking control program. J Appl Behav Anal 1984;17:485-95.
23. Mermelstein R, McIntyre K, Licheteinstein E. Partner support and relapse in smoking cessation programs. $\mathrm{J}$ Consult Clin Psychol 1983;51:465-6.

24. Benjamin EJ, Blaha MJ, Chiuve SE, Cushman M, Das SR, Deo R, et al. Heart Disease and Stroke Stastistics-2017 Update: A Report From the American Heart Association. Circulation 2017 Mar 7;135(10):e146-e6o3. doi: 10.1161/CIR.0000000000000485.

25. Yang Q, Cogswell ME, Flanders WD, Hong Y, Zhang Z, Loustalot F, et al. Trends in cardiovascular health metrics and associations with all-cause and CVD mortality among US adults. JAMA 2012;307:1273-83.

26. Booth MN, Owen N, Bauman A, Clavisi O, Leslie E. Social-cognitive and perceived environment influences associated with physical activity in older Australians. Prev Med 2000;31:15-22.

27. Caserta MS, Gillet PA. Older women's feelings about exercise and their adherence to an aerobic regimen over time. Gerontologist 1998;38:602-9.

28. Castro CM, Sallis JF, Hickman SA, Lee RE, Chen AH. A prospective study of psychosocial correlates of physical activity for ethnic minority women. Psychol Health 1999;14:277-93.

29. Courneya KS, Plotnikoff RC, Hotz SB, Birkett NJ. Social support and the theory of planned behavior in the exercise domain. Am J Health Behav 2000;24:300-8.

30. Eyler AA, Brownson RC, Donatelle RJ, King AC, Brown D, Sallis JF. Physcial activity social support and middle- and older-aged minority women: results from a US survey. Soc Sci Med 1999;49:781-98.

31. Leslie E, Owen N, Salmon J, Bauman A, Sallis JF, Lo SK. Insufficiently active Australian college students: perceived personal, social, and environmental influences. Prev Med 1999; 28:20-7.

32. Levy RL. Social support and compliance: a selective review and critique of treatment integrity and outcome measurement. Soc Sci Med 1983;17:1329-38.

33. Kaplan RM, Hartwell SL. Differential effects of social support and social network on physiological and social outcomes in men and women with type II diabetes mellitus. Health Psych 1987;14:387-98.

34. Schafer LC, McCaul KD, Glasgow RE. Supportive and nonsupportive family behaviors: relationships to adherence and metabolic control in persons with Type I diabetes. Diab Care 1986;9:179-85.

35. Ciechanowski P, Russo J, Katon WJ, Lin EHB, Ludman E, Heckbert S, et al. Relationship styles and mortality in patients with diabetes. Diabetes Care 2010;33:53944.

36. Trief P, Sandberg JG, Ploutz-Snyder R, Brittain R, Cibula D, Scales K, et al. Promoting couples collaboration in types 2 diabetes: the Diabetes Support Project Pilot Data. Fam Syst Health 2011;29:235-61.

37. Roblin DW. The potential of cellular technology to mediate social networks for support of chronic disease self-management. J Health Commun 2011;16:59-76.

38. Tang TS, Brown MB, Funnell NM, Anderson RM. Social support, quality of life, and self-care behaviors among African Americans with type 2 diabetes. Diabetes Educ 2008;34:266-76.

39. Zhang X, Norris SL, Gregg EW, Beckles G. Social support and mortality among older people with diabetes. Diabetes Educ 2007;33:273-81.

40. Sacco WP, Yanover T. Diabetes and depression: the role of social support and medical symptoms. J Behav Med 2006;29:523-31. 